\title{
Determination of Genome Size and Chromosome Number of a Ziziphus Species ( $Z$. mauritiana Lam.) from Eastern Senegal
}

\author{
Hamidou F. Sakhanokho \\ U.S. Department of Agriculture, Agricultural Research Service, Thad Cochran \\ Southern Horticultural Laboratory, 810 Highway 26W, Poplarville, MS 39470
}

\author{
Nurul Islam-Faridi \\ U.S. Department of Agriculture, Forest Service, Southern Research Station, \\ Southern Institute of Forest Genetics, Forest Tree Molecular Cytogenetics \\ Laboratory, College Station, TX 77843 \\ Barbara J. Smith \\ U.S. Department of Agriculture, Agricultural Research Service, Thad Cochran \\ Southern Horticultural Laboratory, 810 Highway 26W, Poplarville, MS 39470
}

Additional index words. ber, jujube, India jujube, nuclear DNA content, octoploid

\begin{abstract}
Ziziphus mauritiana Lam. is a widespread shrub or tree of the Sahel region, where it grows wild and is used for various purposes, including nutrition, medicine, and firewood. Current domestication programs focus on using the local species as rootstock for the improved imported Asian cultivars to provide tolerance to pests and diseases. The plant plays an increasing economic role in the livelihoods of local Sahelian populations, but despite this there is little genetic information about it. The purpose of our study was to determine the genome size estimate and chromosome numbers of $Z$. mauritiana germplasm collected from eastern Senegal, West Africa. Genome size estimates were determined using flow cytometry, and chromosome count was achieved using chromosome spreads of actively growing root tips. The mean, median, minimum, and maximum genome size estimates (1Cx-DNA) of $Z$. mauritiana were 418.74 Mb, 417.45 Mb, 410.72 Mb, and 432.12 Mb, respectively. Plants of the germplasm investigated were found to be octoploid with a chromosome number of $2 n=$ $8 x=96$. The genetic information gathered in this study can be useful for phylogenetic studies, sequencing projects, and domestication programs that focus on controlled pollination for the development of improved $Z$. Mauritania cultivars in the Sahel region.
\end{abstract}

The genus Ziziphus belongs to the family Rhamnaceae and consists of $\approx 40$ species of spiny shrubs and trees (Owolarafe et al., 2020; Patel et al., 1988). Among these 40 species is Ziziphus mauritiana Lam., which is also known as Indian jujube or ber, and is native to Asia and Africa (Ramar et al., 2020). The two most important horticultural Ziziphus species

Received for publication 23 Sept. 2021. Accepted for publication 22 Nov. 2021.

Published online 25 January 2022.

We thank Denise Hardy and Robin Hayes for their invaluable help with various aspects of this study, including flow cytometry analysis, care of plants in the greenhouse and field, and root tip isolation.

The use of trade, firm, or corporation names in this publication is for the information and convenience of the reader. Such use does not constitute an official endorsement or approval by the U.S. Department of Agriculture, the Agricultural Research Service, or the Forest Service of any product or service to the exclusion of others that may be suitable.

H.F.S. and N.I-F. are co-senior authors.

H.F.S. is the corresponding author. E-mail: Hamidou.Sakhanokho@usda.gov.

This is an open access article distributed under the CC BY-NC-ND license (https://creativecommons. org/licenses/by-nc-nd/4.0/). are Z. mauritiana and Z. jujuba Mill. (Chinese jujube). In contrast to $Z$. jujuba, which is native to the temperate regions of China, $Z$. mauritiana has a strong environmental adaptability and generally grows in semiarid and arid areas, but the plant can tolerate extreme temperatures $\left(-2\right.$ to $50^{\circ} \mathrm{C}$, even though growth and development are affected at both extremes) and severe moisture stress (annual rainfall as low as $80 \mathrm{~mm}$ ) (Awasthi and More, 2009; Liu et al., 2014; Maruza et al., 2017). Also, Z. mauritiana has a high salinity tolerance (Nehra et al., 1983).

Ziziphus species are grown for both their nutritional and ornamental values (Maruza et al., 2017; Shao et al., 2021). Ziziphus mauritiana is currently naturalized in many parts of the world, including tropical Africa, southeastern Asia, Australia, and some archipelagos of the Pacific (Liang et al., 2019; Liu and Cheng, 1995). It is a multipurpose shrub or tree $(1.2-12 \mathrm{~m})$ with ethnomedicinal properties and edible fruit rich in various nutrients. Its fruit has a greater vitamin $\mathrm{C}$ content and is larger than that of Z. jujuba (Liang et al., 2019; Nyanga et al., 2013). Ziziphus mauritiana is used for other purposes, including timber for agricultural implements, furniture, cabinet work, and charcoal (Maruza et al., 2017).

Despite the many beneficial attributes alluded to earlier, genetic studies on Z. mauritiana are limited. Cytological studies on $Z$. mauritiana chromosome numbers $(2 n=24,48,72$, or 96$)$ have been reported, but most of these reports are on Asian accessions (Asatryan and Tel-Zur, 2014; Nehra et al., 1983). Ziziphus mauritiana is widespread in rural sub-Saharan Africa, particularly in the Sahel region, where the species grows in the wild. Attempts for improvement often are limited to using the Sahel species as rootstocks for improved Asian cultivars (Danthu et al., 2004; Sanou et al., 2014). This is achieved through grafting of mature plants or micrografting of in vitro propagated explants, but this approach generally depends on the genotype or species of both the scion and rootstock, and sometimes requires serial or repeated grafting or micrografting (Danthu et al., 2001, 2004; Pasternak et al., 2016; Sanou et al., 2014).

It is not clear whether Z. mauritiana is native or was introduced to the Sahel region. What is clear is that genetic investigations needed for successful selection and domestication of improved local cultivars, such as chromosome determination of the $Z$. mauritiana from the Sahel region, are lacking. Molecular tools, including amplified length polymorphism (Singh et al., 2006) and simple sequence repeat (Liang et al., 2019), have been used to assess the genetic diversity of $Z$. mauritiana accessions, but these studies were generally limited to Asian germplasms. In addition, reports on nuclear DNA content analyses have been published, but these studies were mostly done on $Z$. jujuba and its wild ancestor, the sour jujube, $Z$. acidojujuba (Wang et al., 2019). Wu et al. (2013) reported a nuclear DNA content of 0.40 to $0.44 \mathrm{pg}$ C-DNA (393.6-429.6 Mb) for $Z$. jujuba, depending on the cultivar, and $0.45 \mathrm{pg}$ C-DNA for Z. acidojujuba. We are not aware of any reports on the nuclear DNA content or chromosome numbers for $Z$. mauritiana germplasms from sub-Saharan Africa. Therefore, the objectives of our study were to determine nuclear DNA estimates and ploidy level of $Z$. mauritiana germplasm collected in Senegal from the Sahel region.

\section{Materials and Methods}

Plant material. Seeds, collected in three different populations from 15 different trees in eastern Senegal, were dried, scarified with 98\% sulfuric acid (Fisher Scientific, Hampton, $\mathrm{NH}$ ) for $10 \mathrm{~min}$, and then rinsed at least three times for $\approx 1$ min each time with tap water to remove any acid residues completely. The rinsed seeds were sown and germinated in soil-containing pots in the greenhouse for flow cytometry analysis and cytology investigation. Fully developed seedlings (Fig. 1) were used to harvest leaves and root tips for flow cytometry and cytology studies, respectively.

Nuclear DNA content determination. More than 40 seedlings were obtained from the seeds sown in pots in the greenhouse. Among these plants, 10 seedlings were selected randomly for flow cytometry analysis using procedures 


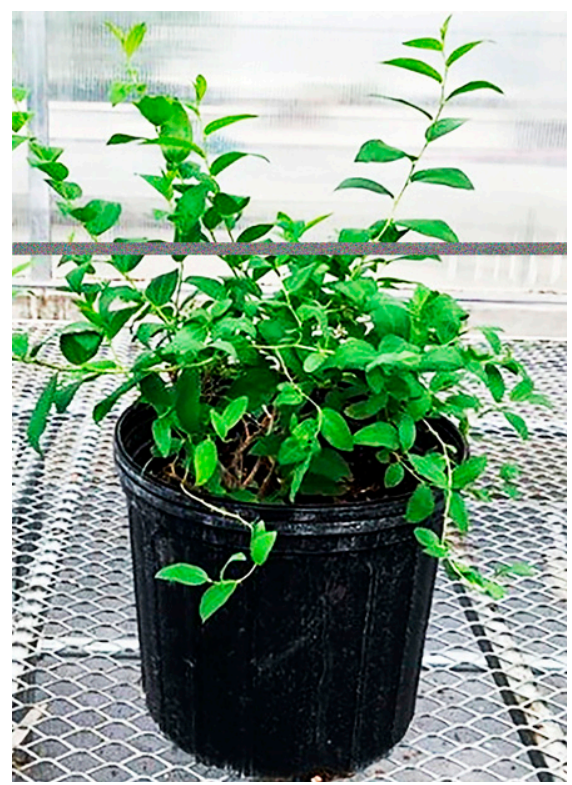

Fig. 1. Ziziphus mauritiana Lam. seedling. Leaves and root tips of seedlings were used for genome size estimate determination and chromosome spread investigation, respectively.

described previously (Islam-Faridi et al., 2020b; Sakhanokho et al., 2020) with minor changes. In total, 10 seedlings were used for flow cytometry analysis. Three different fresh leaves (or replicates) were collected from each seedling, and each leaf was co-chopped in 0.5 $\mathrm{mL}$ nuclei extraction buffer with that of the internal standard Sorghum bicolor 'Tx623' (2C $1.67 \mathrm{pg}$ ) (Price et al., 2005) of equal size $\left(\approx 0.5 \mathrm{~cm}^{2}\right)$ and resuspended in $500 \mu \mathrm{L}$ nuclei extraction buffer. Large debris was removed from the extraction buffer through a $50-\mu \mathrm{m}$ filter before adding a staining solution consisting of $20 \mathrm{~mL}$ staining buffer per sample mixed with $120 \mu \mathrm{L}$ propidium iodide solution, $60 \mu \mathrm{L}$ RNase solution (05-5022; Sysmex Partec GmbH, Görlitz, Germany), and 5\% polyvinylpyrrolidone-40,000 (PVP-40; Sigma-Aldrich, St. Louis, MO). Aluminum foil was used to cover and protect the mixture against light before incubation in a refrigerator at $4{ }^{\circ} \mathrm{C}$ for 15 min. A BD Accuri C6 flow cytometer and BD Accuri C6 software (version 1.0.264.21; BD BioSciences, Ann Arbor, MI) were used for nuclear DNA content analysis. At least 3000 nuclei were analyzed per run. The genome size was determined using the formula Sample 2C-value (in picograms) = Reference $2 \mathrm{C}$-value $\times[($ Sample $2 \mathrm{C}$ mean peak $) /($ Reference $2 \mathrm{C}$ mean peak)], and genome sizes were converted to megabases $(\mathrm{Mb})$ using the equation $1 \mathrm{pg}=978 \mathrm{Mb}$ (Doležel et al., 2003). The sample monoploid $1 \mathrm{Cx}$ value (in picograms) was calculated by dividing the $2 \mathrm{C}$ value by the ploidy level $(x=8)$ of $Z$. mauritiana (Greilhuber et al., 2005).

Chromosome count. Ten seedlings were selected randomly and transferred to pots containing potting media (MetroMix SunGro SB-650; Sun Gro Horticulture, Agawam, MA), including Osmocote Classic (3- to 4-month)
Slow Release 19-6-12 fertilizer (ICL Fertilizers, Dublin, $\mathrm{OH}$ ) for better growth. Chromosome spread preparations were achieved by following procedures described previously (Jewell and Islam-Faridi, 1994; Sakhanokho et al., 2020) with some minor modifications. In brief, actively growing root tips about $1.0 \mathrm{~cm}$ long were harvested and pretreated immediately treated with $2.5 \mathrm{~mm} 8$-hydroxyquinoline for $4.0 \mathrm{~h}$ in the dark at room temperature $\left(22\right.$ to $\left.24^{\circ} \mathrm{C}\right)$, rinsed with double distilled water, then fixed in $95 \%$ ethanol:glacial acetic acid, and stored at room temperature overnight before processing for enzyme digestion for chromosome spread. For plants used for chromosome analysis, at least 20 root tips and 32 chromosome spreads were evaluated. Fixed root tips were rinsed with deionized water, mildly hydrolyzed ( $0.2 \mathrm{~N}$ hydrogen chloride) at $60{ }^{\circ} \mathrm{C}$ for $10 \mathrm{~min}$, rinsed with deionized water, and then rinsed in cold $0.01 \mathrm{~m}$ citrate buffer (20-30 min standing at room temperature) before enzyme digestion. The enzyme mixture consisted of $2 \%$ cellulase RS (w/v), $1 \%$ macerozyme R10 (w/v) (Yakult Pharmaceutical Ind.
Co., LTD., Japan), 2\% pectolyase Y23 (w/v) (Kyowa Chemical Products, Co., LTD., Japan), $30 \%$ cellulase (v/v) (C2730, Sigma-Aldrich), $30 \%$ pectinase $(\mathrm{v} / \mathrm{v})(\mathrm{P} 2611$, Sigma-Aldrich), and $40 \% \quad 0.01 \mathrm{~m}$ citrate buffer $(\mathrm{pH} 4.5)$. The enzyme digestion time varied (24-35 $\mathrm{min}$ ) based on the thickness of root tips, and chromosome spreads were stained with $1 \%$ azure B (SigmaAldrich), dried overnight in a $37^{\circ} \mathrm{C}$ incubator, and made permanent with a drop of Permount (Fisher Scientific, Fair Lawn, NJ). Chromosome spreads were viewed under a $63 \times$ plan apochromatic objective, and digital images were recorded under a green filter using bright field microscopy (AxioImager M2; Carl Zeiss, Göttingen, Germany). The chromosome spread images were processed with Adobe Photoshop CC2019 (Adobe Inc., San Jose, CA).

\section{Results and Discussion}

Flow cytometry. In our investigation, the genome size of $Z$. mauritiana was determined

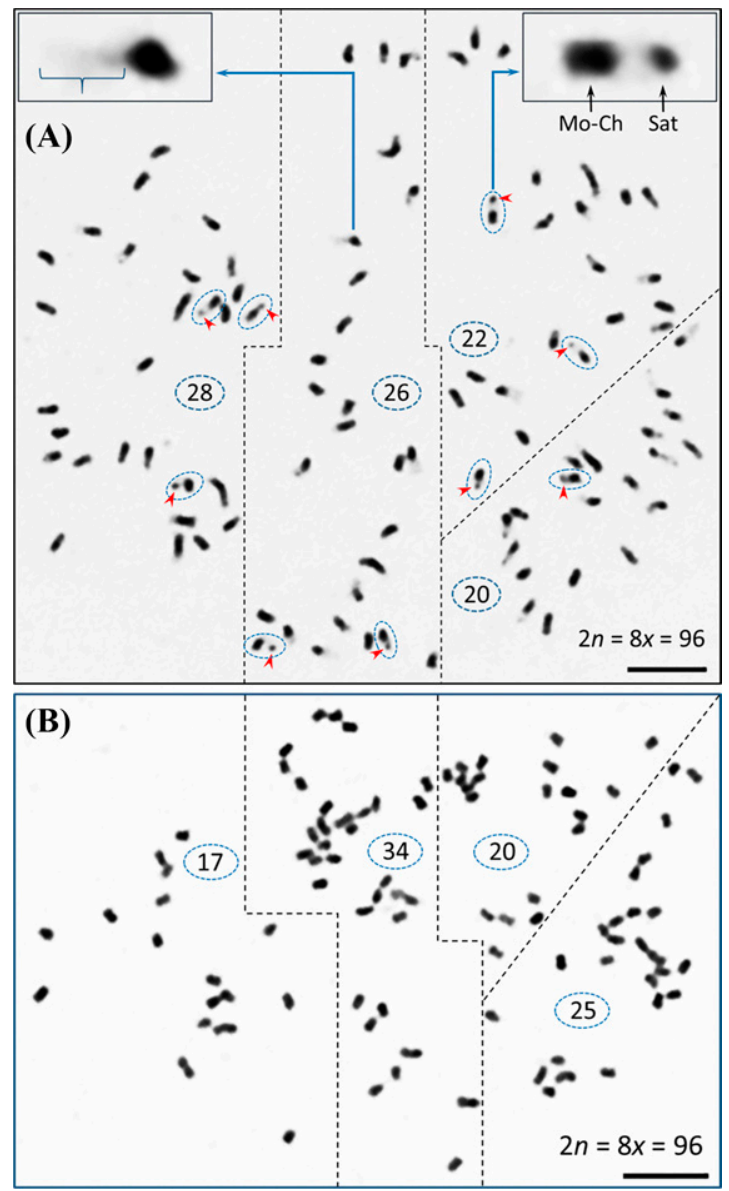

Fig. 2. Somatic chromosome spreads of Ziziphus mauritiana Lam. stained with azure B. (A) A very late-prophase (some of the chromosomes still showing lightly stained euchromatin regions at the end of the chromosomes) cell contained 96 well-separated chromosomes $(2 n=8 x=96)$. Partitioning the chromosome spread into sections facilitated counting the chromosomes $(28+26+22+$ $20=96$ ). Some of the prominent satellites (arrowheads) are associated with their mother chromosomes (circled along with the satellites). (Top-right insert) An enlarged image of a satellite chromosomes (Mo-Ch, mother chromosome; Sat, satellite). (Top-left insert) An enlarged image of a late-prophase chromosome with lightly stained euchromatin region (brace) that is still being condensed. (B) A complete somatic metaphase chromosome spread $(2 n=8 x=96)$ of Ziziphus mauritiana. Partitioning the chromosome spread into sections facilitated the counting of the chromosomes $(17+34+20+25=96)$. Scale bars $=5 \mu \mathrm{m}$. 
Table 1. Analysis of variance for nuclear DNA content estimate (2C-DNA, measured in picograms) of Ziziphus mauritiana Lam. plants from three populations of eastern Senegal, West Africa.

\begin{tabular}{lrcccc}
\hline Source & df & Sum of squares & Mean square & F value & $P$ value $>$ F value \\
\hline Plant & 9 & 0.20532334 & 0.02281370 & 2.20 & $0.0737^{\mathrm{NS}}$ \\
Population & 2 & 0.00478616 & 0.00239308 & 0.23 & $0.7961^{\mathrm{NS}}$ \\
Error & 18 & 0.18656580 & 0.01036477 & & \\
Corrected total & 29 & 0.42555321 & & & \\
\hline
\end{tabular}

Ten plants were used for each one of the three populations to perform analysis of variance for nuclear DNA content determination. To determine the estimates of the $2 \mathrm{C}$-DNA values between and within plants, the analysis of variance was performed using 10 plants. Three replicates or runs per plant, for a total of 30 runs, were analyzed by flow cytometry.

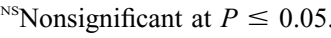

using 10 randomly selected plants derived from seeds of eastern Senegal, in the Sahel region. For all 30 samples run individually, flow cytometry analysis showed a single peak almost gesting that all samples analyzed had the same ploidy and there was no within-genome size variation (Table 1). Also, there was no significant difference $(P \leq 0.05)$ among the three $Z$. mauritiana populations (Table 1). Analysis of the relative DNA contents of $Z$. mauritiana with the internal standard S. bicolor 'Tx623' showed two peaks representing the G1 nuclei of Z. mauritiana and S. bicolor 'Tx623', respectively (Fig. 2). All 30 runs included in the flow cytometry analysis fall within the acceptable range (i.e., less than $5 \%$, as previously specified) (Doležel and Bartoš, 2005). The actual cv values of the samples analyzed fell within the range of $1.8 \%$ to $3.9 \%$. The basic statistics for the samples analyzed are shown in Table 2, where the mean 2C-DNA and monoploid $1 \mathrm{Cx}$ values of samples analyzed were $3.43 \pm 0.05 \mathrm{pg}$ and $418.74 \pm 5.77$ $\mathrm{Mb}$, respectively. The mean monoploid genome size of $Z$. mauritiana ranged from 410.72 to $432.12 \mathrm{Mb}$, with a median value of $417.45 \mathrm{Mb}$ (Table 2). Most of the genomic information on Ziziphus species is related to $Z$. jujuba, for which the entire genome has been sequenced (Huang et al., 2017; Liu et al., 2014). Genome size variation within two diploid Ziziphus species, Z. jujuba [ $(2 n=2 x=24)$ and $Z$. acidojujuba $(2 n=2 x=24)]$, was reported recently (Wang et al., 2019). The genome size of $Z$. jujuba ranged from 300.77 to $640.94 \mathrm{Mb}$ and that of $Z$. acidojujuba varied from 346.93 to $489.44 \mathrm{Mb}$ (Wang et al., 2019). Moreover, genome size estimates of 462.97 $\mathrm{Mb}$ for a wild diploid Z. mauritiana and $1349.73 \mathrm{Mb}$ for 'Tanan No. 1', a hexaploid $(2 n=6 x=72)$ cytotype of $Z$. mauritiana, was reported recently (Wang et al., 2018, 2019). The average and median values $(410.72 \mathrm{Mb}$ and $417.45 \mathrm{Mb}$, respectively) we found for the octoploid $(2 n=8 x=96)$ are closer to the genome size estimate of the diploid cytotype consistently at the same channel (Fig. 2), sug-

mentioned earlier. The available data on genome size estimates of $Z$. mauritiana, although limited, suggest a strong intraspecific genome size variation for the Indian jujube. A high intraspecific genome size variation was reported in Z. jujuba and Z. acidojujuba as well (Wang et al., 2019). Factors that can affect plant nuclear DNA include the internal standard used and environmental conditions, so a more comprehensive investigation involving a more diverse $Z$. mauritiana collection of germplasms consisting of both cultivars, and wild species of all ploidy levels from Asia and Africa, and growing under the same conditions is necessary to assess the extent of this intraspecific variation.

Chromosome count. Root tips collected from Z. mauritiana seedlings (Fig. 1) were used to prepare chromosome spreads. The advantage of using seedlings over germinating seeds is that the former is a nondestructive method, which allows for repetitive harvesting of root tips for chromosome spread preparation if needed. Another advantage of this method is that it allows for the identification and preservation of individual plants with important genetic traits to be used as potential genetic materials for breeding and selection programs. Also, the use of pollen mother cells for meiocyte chromosome spread studies, although not destructive to the whole plant, is time sensitive because flowers may not be readily available throughout the year. Chromosomes of $Z$. mauritiana are difficult to count because of their small size and high number. Therefore, high-quality chromosome spreads, preferably at prometaphase or very late prophase (Fig. 2A), are necessary not only for accurate chromosome counts, but also for use in fluorescent in situ hybridization studies for structural and organizational details. Sometimes overlapped chromosomes make counting of the actual number of chromosomes difficult or impossible when the species' chromosomes are very small. This phenomenon happens because, during metaphase, the chromosomes tend to gather at the equatorial plane. In

Table 2. 2C and 1Cx nuclear DNA content, and 1Cx monoploid genome size of an octoploid $(2 n=$ $8 x=96$, with basic number $x=12$ ) Sahelian Ziziphus mauritiana Lam. determined by flow cytometry.

\begin{tabular}{lcrrrrr}
\hline Variable & $\mathrm{n}$ & Mean & \multicolumn{1}{c}{ SD } & Median & Minimum & Maximum \\
\hline 2C-DNA (pg) & 30 & 3.43 & 0.05 & 3.41 & 3.36 & 3.53 \\
1Cx-DNA (pg) & 30 & 0.43 & 0.01 & 0.43 & 0.42 & 0.44 \\
1Cx-DNA (Mb) & 30 & 418.74 & 5.77 & 417.45 & 410.72 & 432.12 \\
\hline
\end{tabular}

general, chromosomes spreads are well separated during very late prophase or prometaphase, which enables the counting of the exact chromosome number. Sometimes the prominent satellite associated with the nucleolus organizer region (the site of the major $35 \mathrm{~S}$ recombinant RNA gene) may detach from the mother chromosomes (Fig. 2A), which may thus result in a miscount of the chromosome number (Islam-Faridi et al., 2020a). We counted the chromosome number from metaphase and prometaphase, and the very late prophase stages to make sure the count was accurate (Fig. 2, Supplemental Figs. 1-6).

Ziziphus mauritiana has a complex genome (Huang et al., 2017; Nehra et al., 1983; Pradeep and Jambhale, 2000) with a basic chromosome number of $x=12$ and cytotypes including diploid $(2 n=2 x=24)$, tetraploid $(2 n=4 x=48)$, pentaploid $(2 n=5 x=60)$, hexaploid $(2 n=$ $6 x=72)$, and octoploid $(2 n=8 x=96)$. In our study, only the octoploid cytotype was identified (Fig. 2, Supplemental Figs. 1-6). Octoploidy was reported in Indian wild species (Nehra et al., 1983). Cytological analyses involving germplasms collected from various Sahel locations are necessary to determine whether other ploidy types are present in this region. The local Sahelian accessions are characterized by their small fruit size compared with the Asian improved cultivars (Kalinganire et al., 2012). Very little research has focused on $Z$. mauritiana in the Sahel region, and most improvement efforts are geared toward using the local Z. mauritiana as rootstock for the Asian cultivars, which are generally tetraploid (Asatryan and Tel-Zur, 2014; Nehra et al., 1983); however, these cultivars are often susceptible to several local pests and diseases (Kalinganire et al., 2012).

\section{Conclusion}

Genome size estimate of $Z$. mauritiana plants from eastern Senegal, in the Sahel region, was determined for the first time. Chromosome analysis of the species revealed only an octoploid $(2 n=8 x=96)$ cytotype. In recent years, domestication programs have created extensive $Z$. mauritiana germplasm collections in some Sahelian countries such as Burkina Faso, Niger, Mali, and Senegal for the purpose of domestication of the species (Kalinganire et al., 2012). However, these programs generally rely on using the local $Z$. mauritiana as rootstock for the improved imported cultivars. If the Sahel region is to take full advantage of the pest and drought tolerance of the local germplasms, a controlled hybridization between native and imported germplasms is needed, which requires some prior basic understanding of the genetics (e.g., genome size and ploidy) of the West African species. Very little research has been done on $Z$. mauritiana in the Sahel region, and any breeding program, especially if based on controlled hybridization, will require some basic understanding of the species' genetics. The results of our study are a contribution toward that goal. 


\section{Literature Cited}

Asatryan, A. and N. Tel-Zur. 2014. Intraspecific and interspecific crossability in three Ziziphus species (Rhamnaceae). Genet. Resources Crop Evol. 61:215-233, https://doi.org/10.1007/s10 722-013-0027-8.

Awasthi, O.P. and T.A. More. 2009. Genetic diversity and status of Ziziphus in India. Acta Hort. 840:33-40.

Danthu P., B. Hane, M. Touré, P. Sagna, M Sagna, S. Bâ, M.A. deTroyer, and P. Soloviev. 2001. Microgreffage de quatre espéces ligneuses sahéliennes (Acacia senegal, Faidherbia albida, Tamarindus indica et Ziziphus mauritiana) en vue de leur rajeunissement. Tropicultura 19:43-47.

Danthu, P., M.A. Touré, P. Soloviev, and P. Sagna. 2004. Vegetative propagation of Ziziphus mauritiana var. Gola by micrografting and its potential for dissemination in Sahelian zone. Agrofor. Syst. 60:247-253, https://doi. org/10.1023/B:AGFO.0000024415.22907.bc.

Doležel, J. and J. Bartoš. 2005. Plant DNA flow cytometry and estimation of nuclear genome size. Ann. Bot. 95:99-110, https://doi.org/10.1093/ aob/mci005.

Doležel, J., J. Bartoš, H. Voglmayr, and J. Greilhuber. 2003. Nuclear DNA content and genome size of trout and human. Cytometry 51:127-129, https://doi.org/10.1002/cyto.a.10013.

Greilhuber, J., J. Doležel, M.A. Lysak, and M.D. Bennett. 2005. The origin, evolution, and proposed stabilization of the terms 'genome size' and 'C-value' to describe nuclear DNA contents. Ann. Bot. 95:255-260, https://doi.org/ 10.1093/aob/mcl077.

Huang, J., R. Chen, and X. Li. 2017. Comparative analysis of the complete chloroplast genome of four known Ziziphus species. Genes (Basel) 8:340, https://doi.org/10.3390/genes8120340.

Islam-Faridi, N., M.E. Mason, J.L. Koch, and C.D. Nelson. 2020a. Cytogenetics of Fraxinus man$d$ shurica and $F$. quadrangulata: Ploidy determination and rDNA analysis. Tree Genet. Genomes 16:26, https://doi.org/10.1007/s11295020-1418-6.

Islam-Faridi, N., H.F. Sakhanokho, and C.D. Nelson. 2020b. New chromosome number and cytomolecular characterization of the African Baobab (Adansonia digitata L.): The Tree of Life. Sci. Rep. 10:13174, https://doi.org/10.1038/s41598020-68697-6.

Jewell, D.C. and M.N. Islam-Faridi. 1994. Details of a technique for somatic chromosome preparation and C-banding of maize, p. 484-493. In: M. Freeling and V. Walbot (eds). The maize handbook. Springer-Verlag, Dordrecht, The Netherlands.

Kalinganire, A., C. John, J.C. Weber, and S. Coulibaly. 2012. Improved Ziziphus mauritiana germplasm for Sahelian smallholder farmers: First steps toward a domestication programme. For. Trees Livelihoods 21:128-137, https://doi. org/10.1080/14728028.2012.715474.

Liang, T., W. Sun, H. Ren, I. Ahmad, N. Vu, and J. Huang. 2019. Genetic diversity of Ziziphus mauritiana germplasm based on SSR markers and ploidy level estimation. Planta 249(6): 1875-1887, https://doi.org/10.1007/s00425-01903133-2.

Liu, M.J. and C.Y. Cheng. 1995. A taxonomic study on the genus Ziziphus. Acta Hort. 390:161-165.

Liu, M.J., J. Zhao, Q.L. Cai, G.C. Liu, J.R. Wang, Z.H. Zhao, P. Liu, L. Dai, G. Yan, W.J. Wang, X.S. Li, Y. Chen, Y.D. Sun, Z.J. Liu, M.J. Lin, J. Xiaom, Y.Y. Chen, X.F. Li, B. Wu, Y. Ma, J.B. Jian, W. Yang, Z. Yuan, X.C. Sun, Y.L. Wei, L.L. Yu, C. Zhang, S.G. Liao, R.J. He, X.M. Guang, Z. Wang, Y.Y. Zhang, and L.H. Luo. 2014. The complex jujube genome provides insights into fruit tree biology. Nat. Commun. 5:5315, https://doi.org/10.1038/ncomms6315.

Maruza, I.M., L. Musemwa, S. Mapurazi, P. Matsika, V.T. Munyati, and S. Ndhleve. 2017. Future prospects of Ziziphus mauritiana in alleviating household food insecurity and illness in arid and semi-arid areas: A review. World Dev. Perspectives 5:1-6, https://doi.org/10.1016/j. wdp.2017.01.001.

Nehra, N.S., P.K. Sareen, and S.D. Chitkara. 1983. Cytological studies in genus Ziziphus. Cytologia (Tokyo) 48:103-107, https://doi.org/10.1508/ cytologia.48.103.

Nyanga, L.K., T.H. Gadaga, M.J.R. Nout, E.J. Smid, T. Boekhout, and M.H. Zwietering. 2013. Nutritive value of masau (Ziziphus mauritiana) fruits from Zambezi Valley in Zimbabwe. Food Chem. 138:168-172, https://doi.org/ 10.1016/j.foodchem.2012.10.016.

Owolarafe, T., K. Salawu, G. Ihegboro, C. Ononamadu, A. Alhassan, and A. Wudil. 2020. Investigation of cytotoxicity potential of different extracts of Ziziphus mauritiana (Lam) leaf Allium cepa model. Toxicol. Rep. 7:816-821, https://doi.org/10.1016/j.toxrep.2020.06.010.

Pasternak, D., A. Nikiema, A. Ibrahim, D. Senbeto, and I. Djibrilla. 2016. How domesticated Ziziphus mauritiana (Lam) spread in the Sahel region of Africa and in Ethiopia. Chron. Hort. 56:22-25.

Patel, B.H., V.R. Upadhyay, C.M. Muralidharan, and G.S. Judal. 1988. Effect of various insecticides on honey bee, Apis florea Fabricius in 'ber' (Zizyphus mauritiana Lamk). Curr. Sci. 57:1199-1200.

Pradeep, T. and N.D. Jambhale. 2000. Ploidy level variations for stomata, chloroplast number, pollen size and sterility in Ber (Ziziphus mauritiana Lamk.). Indian J. Genet. 60(4):519-525.

Price, H.J., S.L. Dillon, G. Hodnett, W.L. Rooney, L. Ross, and J.S. Johnston. 2005. Genome evolution in the genus Sorghum (Poaceae). Ann. Bot 95:219-227, https://doi.org/10.1093/aob/mci015.

Ramar, M.K., Y. Dhayanandamoorthy, S.S. Ramachandran, and R. Kandasamy. 2020. HPLCESI-QqQ based standardization, mutagenic and genotoxic potential of methanol extract of Ziziphus mauritiana Lam leaves. J. Ethnopharmacol. 246:112216, https://doi.org/10.1016/j.jep. 2019.112216.

Sakhanokho, H.F., N. Islam-Faridi, E.M. Babiker, C.D. Nelson, S.J. Stringer, and J.J. Adamczyk, Jr. 2020. Determination of nuclear DNA content, ploidy, and FISH location of ribosomal DNA in Hibiscus hamabo. Scientia Hort. 264:09167, https://doi.org/10.1016/j.scienta.2019.109167.

Sanou, H., D. Sidibé, A. Korbo, and Z. Teklehaimanot. 2014. Rootstock propagation methods affect the growth and productivity of three improved cultivars of Ber in Mali, West Africa. HortTechnology 24:418-423, https://doi.org/ 10.21273/HORTTECH.24.4.418.

Shao, F., S. Wang, S. Zhang, and J. Chen. 2021. Observation of embryo abortion characteristics of Ziziphus jujuba Mill. 'Zhongquiusucui'. HortScience 56:595-602, https://doi.org/10.21273/ HORTSCI15760-21.

Singh, A.K., R.K. Sharma, N.K. Singh, K.C. Bansal, K.R. Koundal, and T. Mohapatra. 2006. Genetic diversity in ber (Ziziphus spp.) revealed by AFLP markers. J. Hort. Sci. Biotechnol. 81:205-210, https://doi.org/10.1080/ 14620316.2006.11512051.

Wang, L., Z. Luo, Z. Liu, J. Zhao, W. Deng, H Wei, P. Liu, and M. Liu. 2019. Genome size variation within species of Chinese jujube (Ziziphus jujuba Mill.) and its wild ancestor sour jujube (Z. acidojujuba Cheng et Liu). Forests 10:460, https://doi.org/10.3390/f10050460.

Wang, L.H., Y. Lv, Z. Luo, P. Liu, and M.J. Liu. 2018. Establishment and application of a method for chromosome ploidy identification and genome size estimation using flow cytometry in Ziziphus jujuba. J. Agr. Biotechnol. 26(3):511520, https://doi.org/10.3969/j.issn. 16747968 . 2018.03.017.

Wu, L.P., Y. Tang, Y.Y. Li, D.N. Yin, and X.M Pang. 2013. Estimation of genome size of Ziziphus jujuba and Z. acidojujuba. J. Beijing For. Univ. 35:77-83. 


\section{Supplemental Information}

Additional chromosome spreads-prophase, prometaphase, and metaphase - of root tip meristems of Ziziphus mauritiana Lam. are shown in this supplemental document. This $Z$. mauritiana cytotype from eastern Senegal, West Africa, is an octoploid jujube species $(2 n=8 x=96)$ with very small chromosomes. In late prophase or prometaphase, cells contain well-separated chromosomes, so these phases are preferred for counting the chromosomes of a species with many small chromosomes for an accurate count. Furthermore, partitioning the chromosome spread into sections facilitates accurate counting of the chromosomes number. In general, chromosomes aggregate at the equatorial plate for separation and tend to overlap during metaphase, sometimes making counting the exact number difficult. Although pretreatment solutions (e.g., 8-hydroxyquinoline, colchicine, or ice cold) inhibit the formation of spindle fibers and chromosome spreads, some residual effects may remain, causing a few chromosomes to overlap or aggregate, especially when the species' chromosome number is high. Chromosome condensation starts at the beginning of prophase; it ceases at the end of metaphase stage and stains dark with acetocarmine, azure B, or Feulgen stains. There are two types of chromatins: heterochromatin (AT rich and highly repetitive, also known as a genepoor region, which stains dark during the early stage of the cell cycle) and euchromatin [a gene-rich region, which stains light (Supplemental Fig. 1, arrowheads)]. In the chromosome spreads (Supplemental Figs. 2-6), the lightly stained areas (euchromatins) can also be visible in early prometaphases. Satellites can be seen in late or prometaphase stages.

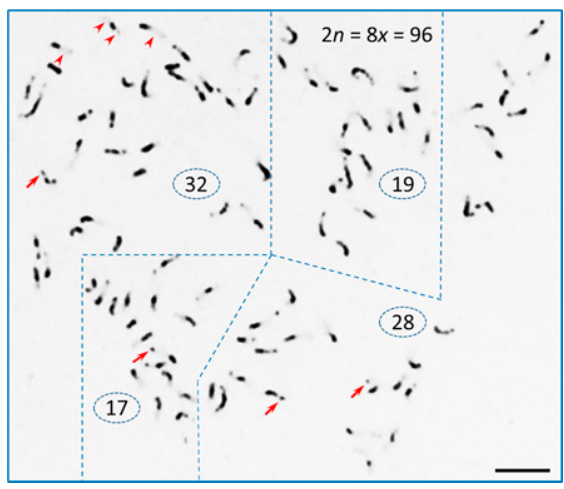

Supplemental Fig. 1. Mid- to early late-prophase cell of $Z$. mauritiana Lam. A well-separated mid-prophase chromosome spread of Ziziphus mauritiana Lam. $(2 n=8 x=96)$. Partitioning the chromosome spread into sections facilitated counting the chromosomes $(32+19+$ $28+17=96)$. Most of the chromosomes shown are lightly stained euchromatins that are still being condensed (arrowheads). A number of chromosomal bodies (most likely the satellites) appear to be detached from the main bodies of the chromosomes (arrows). The total number would be more than 96 chromosomes if counting included these chromosomal bodies or satellites. For this reason, it is not advisable to count the chromosome numbers at the mid-prophase chromosome spreads. $\mathrm{Bar}=5 \mu \mathrm{m}$.

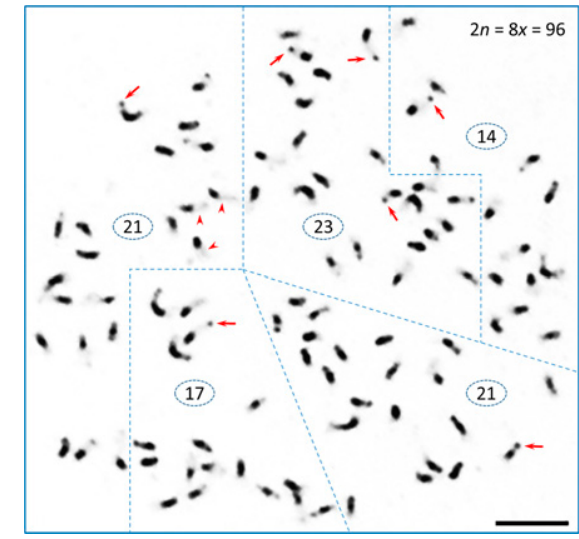

Supplemental Fig. 2. Late-prophase cell of $Z$. mauritiana Lam. A well-separated late-prophase chromosome spread of Ziziphus mauritiana Lam. $(2 n=8 x=96)$. Partitioning the chromosome spread into sections facilitated counting the chromosomes $(21+23+14+21+17=$ 96). Some of the secondary constriction-associated satellites are marked by arrows, and most of the chromosomes shown are euchromatins that are being condensed (stained lightly with azure $\mathrm{B}$, arrowheads). $\mathrm{Bar}=5 \mu \mathrm{m}$

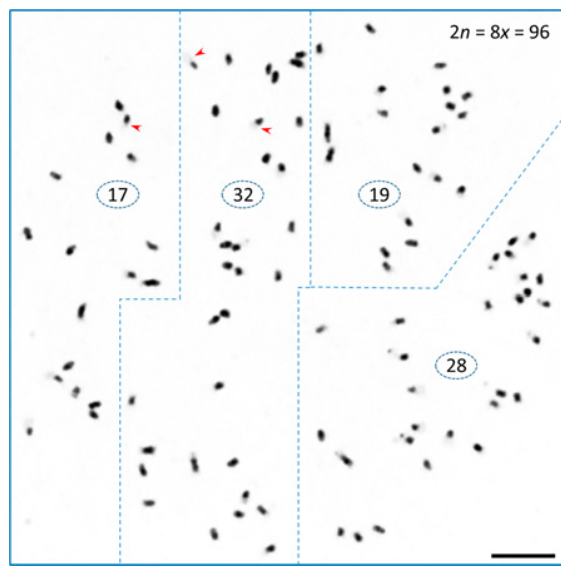

Supplemental Fig. 3. Pro-metaphase cell of $Z$. mauritiana Lam. A well-separated pro-prophase chromosome spread of Ziziphus mauritiana Lam. $(2 n=8 x=96)$. Partitioning the chromosome spread into sections facilitated counting the chromosomes $(17+32+19+$ 28 = 96). Many chromosomes shown are lightly stained euchromatins (arrowheads) that are still being condensed. Bar $=5 \mu \mathrm{m}$. 


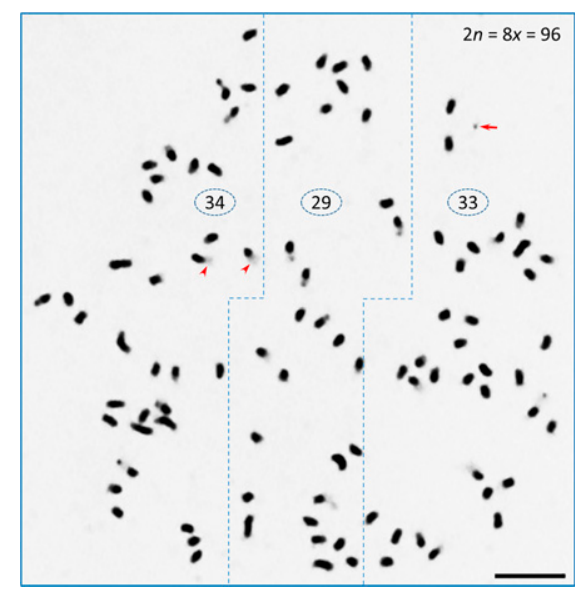

Supplemental Fig. 4. Pro-metaphase cell of $Z$. mauritiana Lam. A well-separated pro-metaphase chromosome spread of Ziziphus mauritiana Lam. $(2 n=8 x=96)$. Partitioning the chromosome spread into sections facilitated counting the chromosomes $(34+29+33=$ 96). Only a few chromosomes shown are lightly stained euchromatins (arrowheads) that are being condensed. An arrow points to a satellite that is detached (separated) from a mother chromosome. $\mathrm{Bar}=5 \mu \mathrm{m}$.

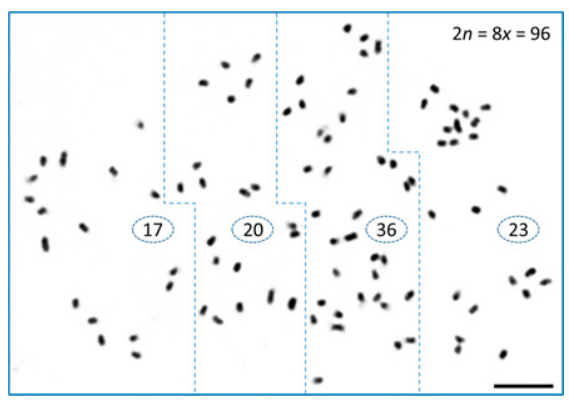

Supplemental Fig. 5. Pro-metaphase/early-metaphase cell of $Z$. mauritiana Lam. A well-separated prometaphase chromosome spread of Ziziphus mauritiana Lam. $(2 n=8 x=96)$. Partitioning the chromosome spread into sections facilitated counting the chromosomes $(17+20+36+23=96)$. Bar $=5 \mu \mathrm{m}$

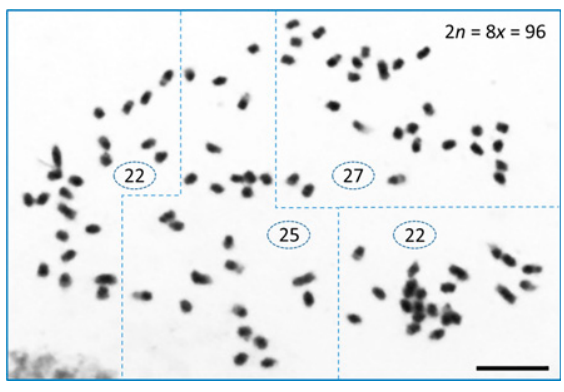

Supplemental Fig. 6. Pro-metaphase/early-metaphase cell of $Z$. mauritiana Lam. A well-separated prometaphase or an early-metaphase chromosome spread of Ziziphus mauritiana Lam. $(2 n=8 x=96)$. Partitioning the chromosome spread into sections facilitated counting the chromosomes $(22+25+27+22=96)$. Bar $=5 \mu \mathrm{m}$ 